\title{
High mortality due to cutaneous melanoma in Norway: a study of prognostic factors in a nationwide cancer registry
}

This article was published in the following Dove Press journal: Clinical Epidemiology

\author{
Trude Eid Robsahm ${ }^{1, *}$ \\ Per Helsing 2,* \\ Yngvar Nilssen' \\ Linda Vos' \\ Syed Mohammad H Rizvi ${ }^{2,3}$ \\ Lars A Akslen ${ }^{4,5}$ \\ Marit B Veierød ${ }^{6}$ \\ 'Cancer Registry of Norway, \\ Oslo, Norway; ${ }^{2}$ Department of \\ Dermatology, Oslo University \\ Hospital, Rikshospitalet, Oslo, \\ Norway; ${ }^{3}$ Institute of Clinical \\ Medicine, University of Oslo, \\ Oslo, Norway; ${ }^{4}$ Centre for Cancer \\ Biomarkers, Department of Clinical \\ Medicine, Section for Pathology, \\ University of Bergen, Bergen, Norway; \\ ${ }^{5}$ Department of Pathology, Haukeland \\ University Hospital, Bergen, Norway; \\ ${ }^{6}$ Oslo Centre for Biostatistics \\ and Epidemiology, Department of \\ Biostatistics, Institute of Basic Medical \\ Sciences, University of Oslo, Oslo, \\ Norway \\ *These authors contributed equally to \\ this work
}

Correspondence: Trude Eid Robsahm Cancer Registry of Norway, PB 53 I 3 Majorstuen, N-0304 Oslo, Norway Tel +47 2245 I 300, +472292 8732 Email trude.eid.robsahm@kreftregisteret. no
Purpose: The purpose of this study was to examine why Norway has the highest rate of mortality due to cutaneous melanoma (CM) in Europe. The Norwegian Malignant Melanoma Registry (NMMR) enables the study of clinical and histopathological characteristics of patients who die due to CM.

Patients and methods: The NMMR and the Norwegian Cause of Death Registry provided data on the clinical and histopathological factors as well as the date and cause of death, through June 2015 for all first invasive CMs diagnosed in 2008-2012 ( $\mathrm{n}=8087)$. Cox regression was used to estimate associations between clinical and pathological factors and CM-specific death. Multiple imputation was used to handle missing data.

Results: The CMs were equally distributed between men (49.9\%) and women (50.1\%), and the median follow-up was 4.0 years (range: $0.08-7.5$ years). Trunk was the most common anatomic site $(48 \%)$, superficial spreading melanoma was the dominant melanoma subtype $(68.2 \%)$, median Breslow thickness was $1.0 \mathrm{~mm}$, ulceration was present in $23 \%$ of CMs, and $91.8 \%$ of cases were in a local clinical stage at diagnosis. Compared to women, men were diagnosed at a higher age, with thicker and more-often-ulcerated tumor, and more often were in advanced clinical stages. During follow-up, 1015 patients died due to CM, representing 52.8\% of all deaths. The nodular subtype made up the dominant proportion of fatal CM cases $(55.3 \%$ in women, $64.6 \%$ in men). Sex, age, anatomic site (trunk), T-stage, ulceration, clinical stage, and having a second primary $\mathrm{CM}$ were associated with increased risk of CM-specific death.

Conclusion: Our data suggest that the high rate of mortality due to CM observed in Norway is attributable to the more advanced stage of the disease at diagnosis. Most high-risk cases occurred in male patients $\geq 70$ years of age. Efforts to improve awareness and secondary prevention of $\mathrm{CM}$, including warning signs of all melanoma subtypes, are required urgently and should be targeted toward men in particular.

Keywords: cutaneous melanoma, mortality, prognostic factors, diagnostic delay, epidemiology

\section{Plain language summary}

We were curious why Norway has the highest rate of mortality due to cutaneous melanoma (CM) in Europe. Data from the Norwegian Malignant Melanoma Registry (NMMR) enabled us to study patient and tumor characteristics among Norwegian patients, their relations to melanomaspecific death, and compare our results with those from other countries. We included all patients diagnosed with their first CM in 2008-2012 ( $\mathrm{n=8087)}$ and linked information on the date and cause of death. We found that trunk was the most common tumor site, superficial spreading melanoma (SSM) was the dominant subtype, median tumor thickness was $1.0 \mathrm{~mm}$, about $20 \%$ of the tumors were ulcerated, and about $10 \%$ of patients had metastases at diagnosis. Compared 
to women, men had thicker tumors and more advanced disease at diagnosis. During follow-up, 1015 patients died from melanoma. Factors that increased the risk of death were male sex, age $\geq 70$ years, tumor site at the trunk, tumor thickness $>1 \mathrm{~mm}$, ulceration, metastases, and having a second tumor. Compared to other countries' data, Norwegian patients have more advanced disease at diagnosis, which can explain our high mortality rate. Our results underline the need for improved public awareness, especially in men.

\section{Introduction}

The incidence of and mortality rates due to cutaneous melanoma (CM) in the Scandinavian countries are among the highest in Europe. ${ }^{1}$ In Norway, CM is the cancer with the steepest increase in incidence after 2000, with an annual increase of $\sim 3.5 \%$, and is now the fifth and fourth most frequent cancer in men and women, respectively (all ages). ${ }^{2}$ The age-adjusted rate of mortality due to $\mathrm{CM}$ has also increased in both sexes, with the highest rate observed in men. ${ }^{2}$ In 2012, the rate of mortality due to CM in Norway was 3.5 per 100,000 (world standard population), which is ranked third worldwide and the highest in Europe (http://globocan.iarc.

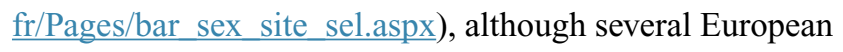
countries have higher or comparable incidence.

Tumor thickness (Breslow), ulceration, and presence of regional or distant metastasis at diagnosis are the most important prognostic factors in $\mathrm{CM} .{ }^{3-5}$ In the Nordic countries, most cases are diagnosed in an early stage of the disease, and in the period 1999-2003, the 5-year relative survival after CM was $\sim 80 \%$ in men and $90 \%$ in women. ${ }^{6}$ In Sweden, increasing $\mathrm{CM}$ incidence has been accompanied by a decrease in tumor thickness and improvement in survival in men. ${ }^{7}$ In Denmark and Norway, the largest increase in incidence has occurred for local-stage tumors. ${ }^{8,9}$ In Northwestern European countries, USA, and Australia, increasing incidence of $\mathrm{CM}$ is accompanied by a stable rate of mortality, ${ }^{10}$ raising the question whether the increase in incidence represents a true increase in risk or whether it is due to better detection, higher awareness, and potentially overdiagnosis of CM. ${ }^{11}$ In Norway, however, the high and increasing mortality rate raises the question whether the $\mathrm{CM}$ diagnoses are delayed, particularly in men.

The NMMR was established in 2008 and now provides the opportunity to study clinical and histopathological characteristics of all primary invasive CM cases, diagnosed in 2008-2012, and the association of these characteristics with CM-specific death. Furthermore, we aimed to discuss the findings in relation to results reported from comparable countries and gain new knowledge to help target secondary prevention in the Norwegian population.

\section{Patients and methods}

\section{Patients}

The Cancer Registry of Norway (CRN) has recorded all cancer diagnoses nationwide since 1953. Mandatory reporting from independent sources ensures completeness and high-quality data. ${ }^{12}$ After $2000,>99 \%$ of all CM cases are morphologically verified. ${ }^{2,12}$ In 2008, the NMMR was established under the CRN, registering additional clinical and histopathological information related to each CM case.

In total, 8120 patients with a first primary invasive CM diagnosis in the period 2008-2012 were identified and included in the study. Sex, age at diagnosis, region of residence, anatomic site, melanoma subtype, Breslow thickness, T-stage, Clark level, presence of ulceration, clinical stage at diagnosis, and information on second primary CM during the study period were obtained from the NMMR.

Information on death and emigration was obtained by linkage to the Causes of Death Registry and the National Population Registry. The end of follow-up was on June 30, 2015. The cause of death is set by the doctor, and reporting to the Causes of Death Registry is mandatory by law (since January 1, 1951). The 10th edition of the World Health Organization's International Classification of Diseases is used. The unique 11-digit personal identification number system, implemented in Norway in 1964, secures the linkages. In all, $33(0.4 \%)$ cases were lost to follow-up, leaving 8087 cases for analyses.

All data were de-identified before analyses. Reporting from cancer-specific registries, with de-identified data, is regulated by the Norwegian law on health registries, needing no further ethical approval.

\section{Clinical and histopathological variables}

Based on age at diagnosis, the $\mathrm{CM}$ cases were divided into age groups ( $<50,50-69$, and $\geq 70$ years). Codes for residential municipality at the time of diagnosis were categorized in accordance with the Norwegian Regional Health Authority regions (South-Eastern, Western, Central, and Northern Norway Regional Health Authorities). As an indicator of dermatologist availability, residential codes were categorized as urban and rural areas.

The anatomic site of the primary tumor was classified according to the International Classification of Diseases for Oncology, Third Edition (ICDO-3) $)^{13}$ and categorized as head/ neck (190.0), trunk (190.1/190.7), upper extremity (190.2), lower extremity (190.3/190.4), and other (190.5/190.6/190.8). Cases without information on the anatomic site (190.9) were categorized as unspecified $(n=477)$. 
Melanoma subtype is registered according to the following ICDO-3 codes: ${ }^{13}$ SSM (M87433), nodular melanoma (NM; M87213), lentigo maligna melanoma (LMM; M87423), acral lentiginous melanoma (ALM; M87443), melanoma unspecified (M87203), and other (M87453/ M87803/M87613). For 2126 cases, information on subtype was not given.

The Norwegian guidelines for the period 2008-2015 advised reporting of Breslow thickness in millimeters to 1 decimal point. ${ }^{14}$ Breslow thickness was categorized as the following T-stages: T1 $(\leq 1.0 \mathrm{~mm}), \mathrm{T} 2(1.01-2.0 \mathrm{~mm}), \mathrm{T} 3$ $(2.01-4.0 \mathrm{~mm})$, and $\mathrm{T} 4(>4.0 \mathrm{~mm})$. Cases without information on Breslow thickness $(n=857)$ were categorized as unspecified.

Information on the Clark level (I-V) and ulceration (present, not present) was used as registered in the NMMR. For a large proportion of cases $(n=3638)$, information on ulceration was not specified. The $\mathrm{CRN}$ coding and classification system follows international standards, ${ }^{12}$ with some modifications for stage as described in the CRN annual report; ${ }^{2}$ based on information on clinical and histopathological notifications for each CM case, metastasis is coded by trained medical coders according to strict rules and local coding practice at the CRN. Clinical stage at diagnosis was categorized as follows: local disease (no metastases), regional metastasis (metastases in regional lymph nodes, satellites, and in-transit metastases), and distant metastasis (organ metastases and nonregional lymph node metastases). Cases without information about metastasis $(\mathrm{n}=1116)$ were categorized as unspecified.

Criteria for a new primary $\mathrm{CM}$ during the study period $(0,1$, or $>1)$ were different melanoma subtype, different anatomic site, or date of diagnosis at least 4 months after the first CM diagnosis.

\section{Statistical analysis}

Descriptive data are presented as frequencies (\%) and medians (ranges). Differences between men and women were tested by the Mann-Whitney test for continuous variables and the chi-square test for categorical variables.

The $\mathrm{CM}$ cases were followed from the date of diagnosis until death, emigration, or end of follow-up (June 30, 2015), whichever occurred first. The traditional Kaplan-Meier estimator overestimates cumulative incidence in the presence of competing risk due to the incorrect assumption of non-informative censoring, ${ }^{15-17}$ thus, cumulative incidence of $\mathrm{CM}$-specific death and that of death from other causes were estimated by a nonparametric method, taking competing events into account. ${ }^{15}$
Cox regression, with the time since date of CM diagnosis as the time scale, was used to study the association between the clinical and histopathological variables and CM-specific death. Results are presented as hazard ratios (HRs) with 95\% confidence intervals (CIs). The melanoma subtype ALM was included in the "other" category due to low numbers, and the Clark level was not included due to the high correlation with T-stage. The incidence of a new primary CM during the study period was modeled as a time-dependent covariate. Interaction between sex and age has previously been reported ${ }^{18}$ and was, thus, evaluated by a likelihood ratio test (with age dichotomized as $<70 / \geq 70$ in complete-case data).

We imputed missing data (anatomic site, melanoma subtype, Breslow thickness, ulceration, and clinical stage) using multiple imputation with chained equations. ${ }^{19} \mathrm{~A}$ combined result was set after running the imputation model 30 times..$^{19}$ In addition, analyses were conducted based on complete-case data.

All statistical analyses were performed using Stata 14 (StatCorp LP, College Station, TX, USA).

\section{Results}

Table 1 shows the characteristics of the total $8087 \mathrm{CM}$ cases, in total and stratified by sex; the cases comprised $50.1 \%$ women and $49.9 \%$ men. The mean age at diagnosis was 64 years, and men were older ( 65 years) than the women (62 years). The majority of the CM cases (61.2\%) resided in areas under the South-Eastern Norway Regional Health Authority, and both sexes were similarly distributed in the regions.

The distribution of $\mathrm{CM}$ with regard to the anatomic site was different for men and women (Table 1) and varied by age (Figure 1). For both sexes, trunk was the most common location $(48.0 \%)$, but it was more common in men (60.4\%) than in women $(35.8 \%)$; women had more leg tumors $(34.0 \% \mathrm{vs}$ $13.0 \%$, respectively). Head/neck tumors were most frequent in patients $\geq 70$ years of age in both sexes (Figure 1).

The dominant melanoma subtype was SSM $(70.6 \%$ in women and $65.8 \%$ in men), followed by NM $(22.8 \%$ in women and $28.6 \%$ in men; Table 1). The proportion of NM was highest in men for all anatomic sites (data not shown), with increasing proportion by age in both sexes $(34.7 \%$ being NM in patients $\geq 70$ years; Figure 1).

Median Breslow thickness was $1.0 \mathrm{~mm}$ in women and $1.1 \mathrm{~mm}$ in men (Table 1). SSM tumors were thinner (median $0.8 \mathrm{~mm}$ ) than NM tumors (median $3.0 \mathrm{~mm}$; data not shown). Men had thicker and more-invasive tumors than women. In women, $56 \%$ of the tumors were in T-stage I and in men, the 
Table I Characteristics of the 8087 CM cases (2008-20I2), total and stratified by sex

\begin{tabular}{|c|c|c|c|c|}
\hline Characteristics & Total & Women & Men & P-value* \\
\hline n (\%) & $8087(100)$ & $4052(50.1)$ & 4035 (49.9) & \\
\hline Age (years), median (range) & $64(2-98)$ & $62(2-98)$ & 65 (14-98) & $<0.001$ \\
\hline Age group, n (\%) & & & & $<0.001$ \\
\hline$<50$ years & $1813(22.4)$ & $1093(27.0)$ & $720(17.8)$ & \\
\hline $50-69$ years & $3417(42.2)$ & $1622(40.0)$ & $1795(44.4)$ & \\
\hline$\geq 70$ years & $2857(35.4)$ & $1337(33.0)$ & $1520(37.6)$ & \\
\hline Regional Health Authority, n (\%) & & & & 0.230 \\
\hline South-Eastern & $4957(61.2)$ & $2473(61.0)$ & $2484(61.6)$ & \\
\hline Western & $1728(21.4)$ & $872(21.6)$ & $856(21.2)$ & \\
\hline Central & $981(12.2)$ & $512(12.6)$ & $469(11.6)$ & \\
\hline Northern & $42 I(5.2)$ & $195(4.8)$ & $226(5.6)$ & \\
\hline Urban-rural area, $n(\%)$ & & & & 0.451 \\
\hline Urban & $3846(47.6)$ & $1944(48.0)$ & $1902(47.2)$ & \\
\hline Rural & $424 I(52.4)$ & $2108(52.0)$ & $2133(52.8)$ & \\
\hline Anatomic site, $n(\%)$ & & & & $<0.001$ \\
\hline Trunk & $3656(48.0)$ & $1368(35.8)$ & $2288(60.4)$ & \\
\hline Head/neck & $1072(14.0)$ & $497(13.0)$ & $575(15.2)$ & \\
\hline Arm & $1055(13.8)$ & $640(16.8)$ & $415(11.0)$ & \\
\hline Leg & $|79|(23.6)$ & $1303(34.0)$ & $488(13.0)$ & \\
\hline Other & $36(0.4)$ & $20(0.6)$ & $16(0.4)$ & \\
\hline Unspecified & 477 & 224 & 253 & \\
\hline Melanoma subtype, n (\%) & & & & $<0.001$ \\
\hline Superficial spreading & 4067 (68.2) & $2129(70.6)$ & $1938(65.8)$ & \\
\hline Nodular & $1527(25.6)$ & $686(22.8)$ & $84 \mid(28.6)$ & \\
\hline Lentigo maligna & $229(3.8)$ & $137(4.6)$ & $92(3.2)$ & \\
\hline Acral & $32(0.6)$ & $20(0.6)$ & $12(0.4)$ & \\
\hline Other & $106(1.8)$ & $42(1.4)$ & $64(2.2)$ & \\
\hline Unspecified & 2126 & 1038 & 1088 & \\
\hline Breslow thickness (mm), median (range) & I $(0.1-70.0)$ & $I(0.1-65.0)$ & I.I (0.I-70.0) & $<0.001$ \\
\hline T-stage, n (\%) & & & & $<0.001$ \\
\hline TI $(\leq 1.0 \mathrm{~mm})$ & $3745(51.8)$ & $2038(56.0)$ & $1707(47.6)$ & \\
\hline $\mathrm{T} 2(\mathrm{I} .0 \mathrm{I}-2.0 \mathrm{~mm})$ & $|56|(2 \mid .6)$ & $786(21.6)$ & $775(21.6)$ & \\
\hline T3 $(2.01-4.0 \mathrm{~mm})$ & $1112(15.4)$ & $469(12.8)$ & $643(18.0)$ & \\
\hline $\mathrm{T} 4(>4.0 \mathrm{~mm})$ & $812(11.2)$ & $352(9.6)$ & $460(12.8)$ & \\
\hline Unspecified & 857 & 407 & 450 & \\
\hline Clark level, n (\%) & & & & $<0.001$ \\
\hline II & I 484 (28.6) & $825(3 \mid .2)$ & $659(25.8)$ & \\
\hline III & $1885(36.2)$ & $927(35.2)$ & $958(37.4)$ & \\
\hline IV & I553 (29.8) & $752(28.4)$ & $801(31.4)$ & \\
\hline v & $273(5.2)$ & $135(5.2)$ & $138(5.4)$ & \\
\hline Unspecified & 2892 & 1413 & 1479 & \\
\hline Ulceration, n (\%) & & & & $<0.001$ \\
\hline Present & $1200(27.0)$ & $508(23.0)$ & $692(30.8)$ & \\
\hline Not present & $3249(73.0)$ & $1693(77.0)$ & $1556(69.2)$ & \\
\hline Unspecified & 3638 & $|85|$ & 1787 & \\
\hline Clinical stage, n (\%) & & & & $<0.001$ \\
\hline Local & $6400(91.8)$ & $3280(93.8)$ & $3120(89.8)$ & \\
\hline Regional metastasis & $352(5.0)$ & $140(4.0)$ & $212(6.2)$ & \\
\hline Distant metastasis & $219(3.2)$ & $77(2.2)$ & $142(4.0)$ & \\
\hline Unspecified & 1116 & 555 & 561 & \\
\hline Second primary CM, n (\%) & & & & $<0.001$ \\
\hline 0 & $785 I(97.0)$ & $3963(97.8)$ & $3888(96.4)$ & \\
\hline I & $215(2.6)$ & $83(2.0)$ & $132(3.2)$ & \\
\hline$>1$ & $21(0.2)$ & $6(0.2)$ & $15(0.4)$ & \\
\hline
\end{tabular}

Note: ${ }^{*} P$-value from testing the difference between men and women.

Abbreviation: CM, cutaneous melanoma. 
A

Location
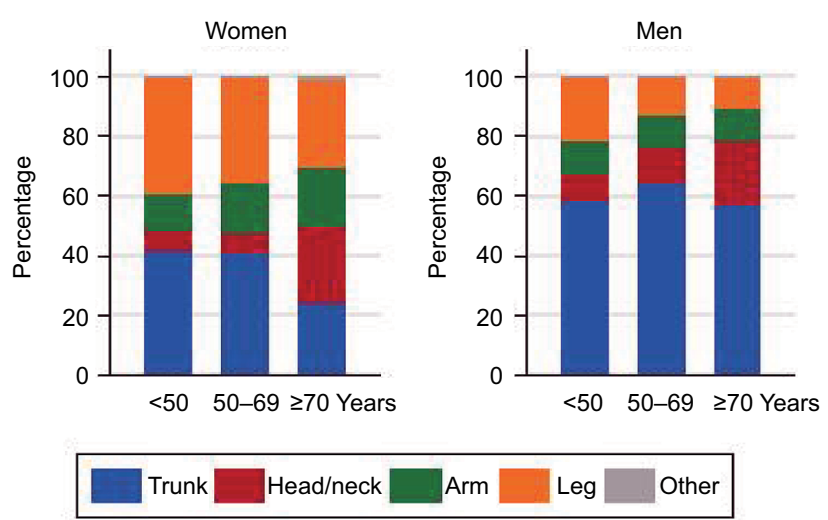

C

T-stage
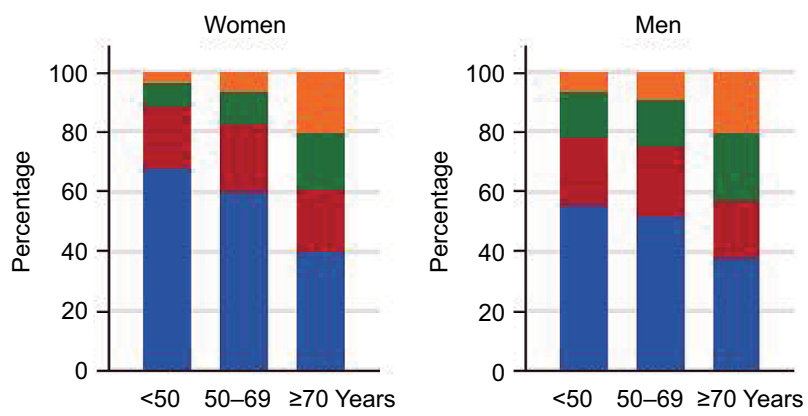

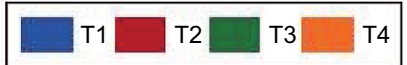

B
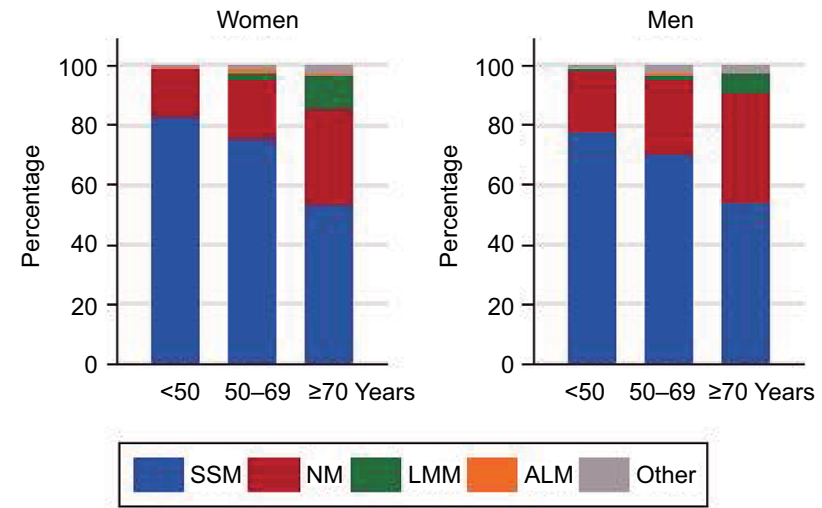

D
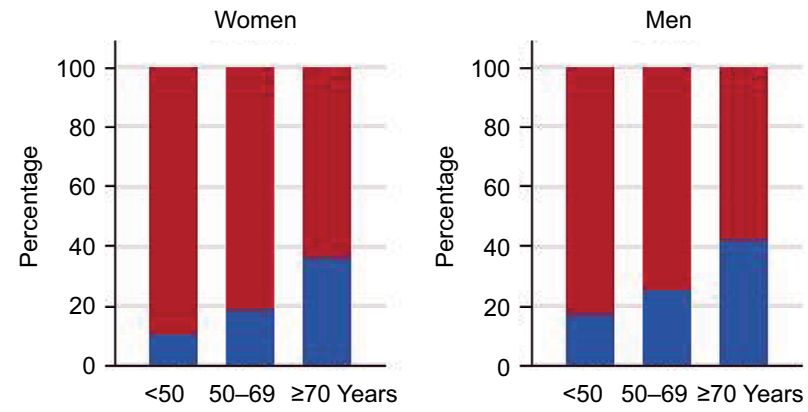

Figure I (A) Anatomic site, (B) melanoma subtype, (C) T-stage, and (D) ulceration in CM cases diagnosed in Norway in 2008-20I2, according to sex and age (n=8087). Abbreviations: CM, cutaneous melanoma; SSM, superficial spreading melanoma; NM, nodular melanoma; LMM, lentigo maligna melanoma; ALM, acral lentiginous melanoma.

proportion was $47.6 \%$. T-stage and Clark level were different for men and women. The proportion of Clark II tumors was $31.2 \%$ in women and $25.8 \%$ in men (Table 1 ). Increasing T-stage with increasing age at diagnosis was seen for both sexes (Figure 1).

Presentation of ulceration was more frequent in men $(30.8 \%)$ than in women $(23 \%$; Table 1$)$. Moreover, the presence of ulceration increased by age (Figure 1) and with increasing T-stage; ulceration was present in $73.8 \%$ of the T4 tumors (data not shown).

In total, $91.8 \%$ of the cases were diagnosed in a local stage, whereas $5 \%$ had regional metastases and 3.2\% had distant metastases (Table 1). Advanced clinical stage at diagnosis was more common in men than in women.

Median time of follow-up was 4.0 years (range 0.08 7.5 years), and during follow-up, 1015 deaths occurred due to $\mathrm{CM}$, representing $52.8 \%$ of all deaths $(\mathrm{n}=1921)$ and $78.7 \%$ of all deaths before the age of 50 years. Figure 2 shows the cumulative incidences of CM-specific death and death due to other causes (2008-2015). After 3 years, the estimated risk of dying from $\mathrm{CM}$ was $9.7 \%$, the risk of dying from other causes was $7.8 \%$, and the odds of being alive were $82.5 \%$. The corresponding numbers after 5 years were $12.5 \%, 12.1 \%$, and $75.5 \%$, respectively. Cumulative incidence plots showed higher risk of CM-specific death in men than in women, as well as an increasing risk of death with increasing age, T-stage, and clinical stage (Figure 3). Low survival was observed for CMs with unspecified T-stage (Figure 3). The NM type comprised the dominant proportion of fatal CM cases $(55.3 \%$ in women and $64.8 \%$ in men), and $70.2 \%$ of patients were in T-stage T3 or T4 (data not shown).

In total, 5010 cases had complete data for the anatomic site, melanoma subtype, Breslow thickness, ulceration, and clinical stage. The percentage distribution per variable, in total and stratified by sex, was quite similar in the simulated data (Table S1).

Sex, age, anatomic site, T-stage, ulceration, clinical stage, and having a second primary CM were associated with 
CM-specific death, both in crude and multivariate analyses, whereas melanoma subtype was associated with CM-specific death in crude analysis only and not after adjustment for

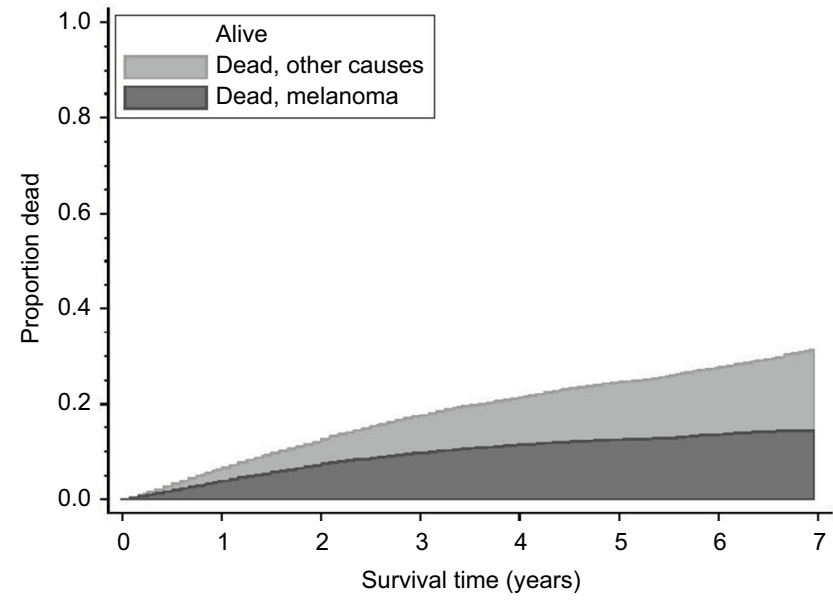

Figure 2 Cumulative incidence of death due to $\mathrm{CM}$ and death from other causes in patients diagnosed in 2008-2012, based on the nonparametric method, taking competing events into account $(n=8087)$.

Abbreviation: CM, cutaneous melanoma.
T-stage (Table 2). Complete-case analyses showed similar results (Table S2). The effect of sex was, however, slightly stronger in patients aged $<70$ years compared to those aged $\geq 70$ years of age (HRs [ $95 \%$ CIs] were 1.41 [1.15-1.74] and 1.17 [0.95-1.45], respectively), but there was no interaction between age and sex.

\section{Discussion}

Our main findings are that male sex and advancing age are independent prognostic factors of $\mathrm{CM}$-specific death and that higher T-stage, presence of ulceration, and advanced clinical stage are associated with male sex and high age, explaining the high mortality rate due to $\mathrm{CM}$ in Norwegian men. The dominant proportion of fatal $\mathrm{CM}$ cases was made up of the NM type. Analyses based on imputed missing data and the complete-case data gave similar results.

Few population-based CM registries with both clinical and histopathological data exist, and results from these registries cover different time periods and geographical
A

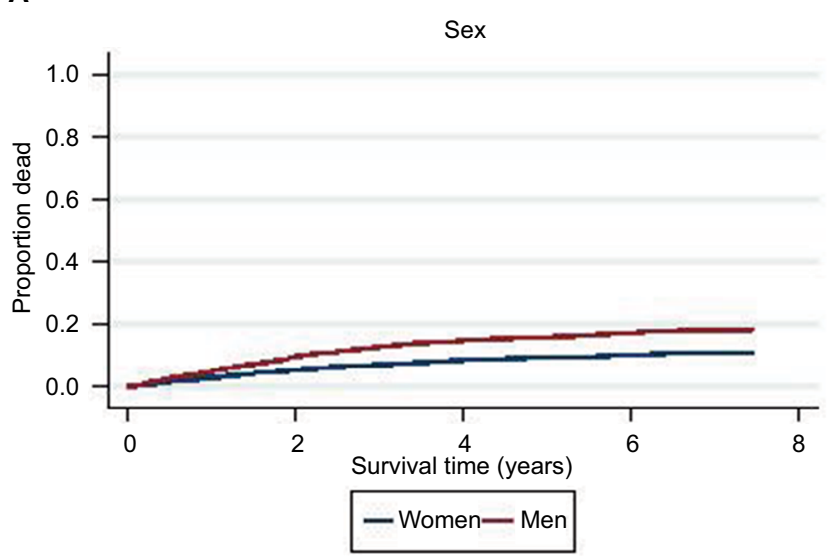

C

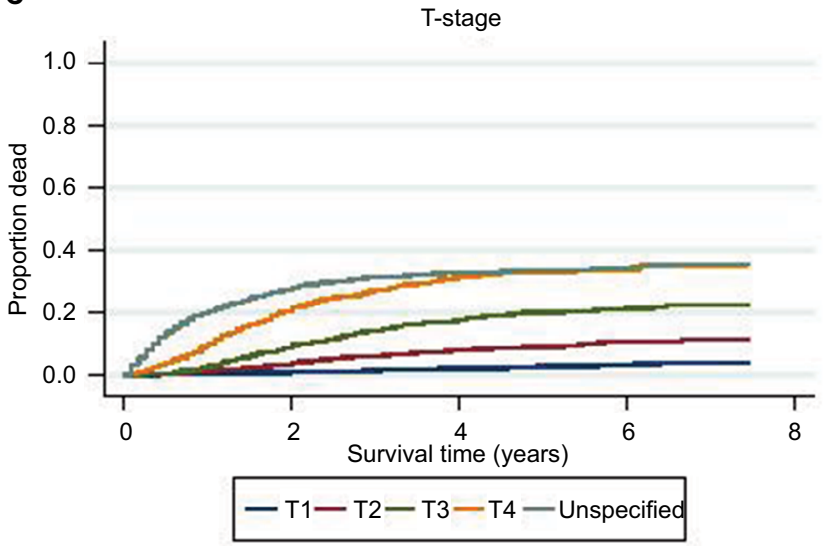

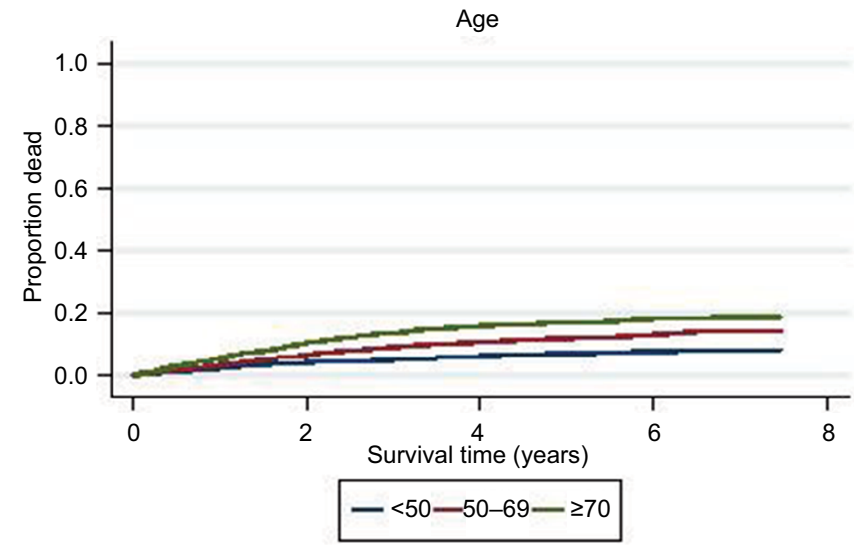

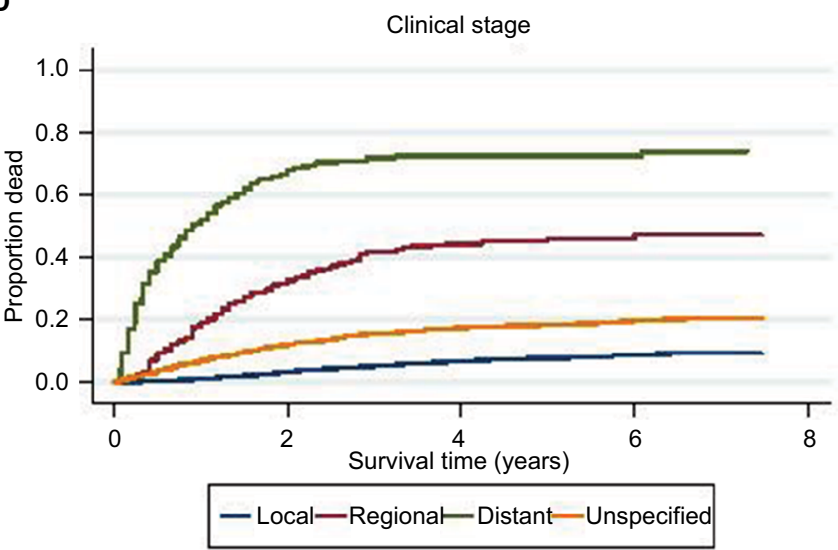

Figure 3 Cumulative incidence of death due to CM according to (A) sex, (B) age groups, (C) T-stage, and (D) clinical stage at diagnosis in patients diagnosed in 2008-20I2 ( $n=8087$ ), based on the nonparametric method, taking competing events into account. Abbreviation: CM, cutaneous melanoma. 
Table 2 HRs for CM-specific death, with $95 \% \mathrm{Cls}$, by sex, age, anatomic site, melanoma subtype, T-stage, ulceration, clinical stage, and having a second primary CM from crude and multivariate analyses $(n=8087)$

\begin{tabular}{|c|c|c|c|c|c|}
\hline \multirow[t]{2}{*}{ Characteristics } & \multirow[t]{2}{*}{ CM-specific death, $n$} & \multicolumn{2}{|c|}{ Crude analysis } & \multicolumn{2}{|c|}{ Multivariate analysis } \\
\hline & & HR & $95 \% \mathrm{Cl}$ & HR & $95 \% \mathrm{Cl}$ \\
\hline \multicolumn{6}{|l|}{ Sex } \\
\hline Women & 359 & 1.00 & & 1.00 & \\
\hline Men & 616 & 1.83 & $1.60-2.08$ & 1.29 & I.II-I.50 \\
\hline \multicolumn{6}{|l|}{ Age (years) } \\
\hline$<50$ & 119 & 1.00 & & 1.00 & \\
\hline $50-69$ & 390 & 1.80 & $1.47-2.21$ & 1.20 & $0.96-1.51$ \\
\hline$\geq 70$ & 466 & 3.05 & $2.49-3.73$ & 1.53 & $1.23-1.91$ \\
\hline \multicolumn{6}{|l|}{ Anatomic site } \\
\hline Trunk & 393 & 1.00 & & 1.00 & \\
\hline Head/neck & 128 & 1.32 & $1.07-1.62$ & 0.78 & $0.6 \mathrm{I}-0.99$ \\
\hline Arm & 85 & 0.77 & $0.6 \mathrm{I}-0.98$ & 0.61 & $0.48-0.79$ \\
\hline Leg & 150 & 0.83 & $0.68-1.01$ & 0.76 & $0.61-0.93$ \\
\hline Other & 12 & 4.33 & $2.35-7.98$ & 1.07 & $0.50-2.26$ \\
\hline \multicolumn{6}{|l|}{ Melanoma subtype } \\
\hline Superficial spreading & 213 & 1.00 & & 1.00 & \\
\hline Nodular & 301 & 4.30 & $3.54-5.22$ & 1.01 & $0.79-1.29$ \\
\hline Lentigo maligna & 9 & 0.91 & $0.46-1.81$ & 0.93 & $0.46-1.86$ \\
\hline Other & 21 & 3.91 & $2.21-6.93$ & 0.67 & $0.40-1.14$ \\
\hline \multicolumn{6}{|l|}{ T-stage } \\
\hline $\mathrm{TI}(\leq \mathrm{I} .0 \mathrm{~mm})$ & 89 & 1.00 & & 1.00 & \\
\hline $\mathrm{T} 2(\mathrm{I} .0 \mathrm{l}-2.0 \mathrm{~mm})$ & 134 & 3.73 & $2.83-4.91$ & 3.21 & $2.43-4.25$ \\
\hline T3 $(2.01-4.0 \mathrm{~mm})$ & 209 & 8.96 & $6.96-11.54$ & 6.17 & $4.63-8.23$ \\
\hline $\mathrm{T} 4(>4.0 \mathrm{~mm})$ & 257 & 21.73 & $17.14-27.55$ & 9.68 & $7.06-13.28$ \\
\hline \multicolumn{6}{|l|}{ Ulceration } \\
\hline Present & 274 & 4.72 & $3.96-5.64$ & 1.34 & I.06-I.7| \\
\hline Not present & 215 & 1.00 & & 1.00 & \\
\hline \multicolumn{6}{|l|}{ Clinical stage } \\
\hline Local & 438 & 1.00 & & 1.00 & \\
\hline Regional metastasis & 156 & 9.06 & $7.58-10.83$ & 4.00 & $3.26-4.90$ \\
\hline Distant metastasis & 159 & 28.51 & $23.63-34.41$ & 16.82 & $12.88-2 \mid .95$ \\
\hline \multicolumn{6}{|l|}{ Second primary CM } \\
\hline 0 & 940 & 1.00 & & 1.00 & \\
\hline I & 30 & 1.43 & $0.99-2.05$ & 2.67 & $1.79-3.99$ \\
\hline$>1$ & 5 & 2.95 & $1.22-7.12$ & 6.17 & $2.51-15.17$ \\
\hline
\end{tabular}

Abbreviations: $\mathrm{Cl}$, confidence interval; $\mathrm{CM}$, cutaneous melanoma; $\mathrm{HR}$, hazard ratio.

areas. ${ }^{7,20-25}$ Although this may complicate comparisons, the present results are discussed based on data from comparable registries.

We found that median age at first CM diagnosis was 64 years, and this is higher than that observed in Swedish (59.5 years, 1990-1999), ${ }^{20}$ Australian (54 years, 1986-1996), and Central European databases (54 years, 1986-1996), ${ }^{21}$ but similar to that reported in the most recent Swedish data (64 years, 2007-2011). ${ }^{7}$ Our finding of increasing risk of CM-specific death by increasing age, even after adjustment for established prognostic factors, is in line with previous studies. ${ }^{20,26}$ Furthermore, we found a weaker effect of sex in CM patients $\geq 70$ years of age, in line with Lasithiotakis et al, ${ }^{26}$ but contrary to the more recent study by Khosrotehrani et al, ${ }^{18}$ suggesting a survival benefit for patients $>60$ years of age (women only).

The anatomic site distribution of CM was in line with previous reports from Norway ${ }^{9,27}$ and Sweden, ${ }^{20}$ with the trunk as the main site $(48.0 \%)$, although more prevalent in men $(60.4 \%)$ than in women $(35.8 \%)$. In agreement with other studies, ${ }^{28,29}$ trunk CM had a less favorable prognosis than $\mathrm{CM}$ at other anatomic sites, which may explain some of the difference in prognosis between the sexes.

SSM was, as expected, the dominant melanoma subtype. However, NM was more prevalent in Norway in the period $2008-2012$ (22.8\% in women and $28.6 \%$ in males) than reported in previous studies: Sweden $(21.0 \%, 1990-1999),{ }^{20}$ Surveillance, Epidemiology, and End Results (SEER) 
program of the National Cancer Institute $(12.6 \%$, 1989 2009), ${ }^{25}$ and Queensland, Australia (15.2\%, 1984-1996). ${ }^{21}$ The median tumor thickness in Norway was $1.0 \mathrm{~mm}(1.1 \mathrm{~mm}$ in men), thicker than that reported in other registries. ${ }^{20,21,25}$ Compared to other studies, we also found a higher proportion of cases with T4 tumors ${ }^{20,21,23-25}$ and fewer with T1. ${ }^{7,20,23,25}$ In the SEER ${ }^{22,25}$ and in Australia, ${ }^{23}$ the reported proportion of T1 tumors was close to $70 \%$, compared to $51.8 \%$ in the current study. Hence, thicker tumors with higher levels of infiltration may explain the higher mortality rate in Norway. In the first 3 years after diagnosis, the highest risk of CM-specific death was seen for cases with unspecified T-stage (Figure 3), and the HR for CM-specific death was at the same level as found for T3 (Table 2). This is in line with recent findings from the USA. ${ }^{30}$

Ulceration is a strong prognostic factor. ${ }^{3-5}$ The proportion of missing data on ulceration in the current study was high, similar to that found in Swedish studies. ${ }^{20,31}$ In Norway, pathologists tend to report on ulceration only when it is present, not when it is absent. When collapsing the groups "unspecified" and "not present", the proportion of ulceration was $14.8 \%$, slightly lower than the proportion of ulceration found in Sweden (16.7\%). Ulceration was more frequent in men, and the occurrence increased with age, further explaining the higher mortality rates in old men.

Clinical stage at diagnosis has also been established as a strong prognostic factor. ${ }^{3-5}$ In our population, $91.6 \%$ of the patients were diagnosed with local disease in 2008-2012 (92.8\% including unspecified stage; Table 1), a lower proportion than that reported from Sweden in 1990-1999 $(95.3 \%)^{20}$ and Central Europe in 1984-1996 (96.2\%) ${ }^{21}$ and comparable to that in the SEER cohort in 1989-2009 (92.4\%). ${ }^{25}$ Thus, Norwegian CM patients seem to be diagnosed in a moreadvanced disease stage, explaining the lower survival relative to $\mathrm{CM}$ patients in other registries. Local disease was also less common in men (89.6\%) than in women $(93.7 \%)$, contributing to higher mortality rates among men.

The high proportions of T3 and T4 tumors, as well as $\mathrm{NM}$, among the fatal CM cases are of special interest. In data from SEER ${ }^{22}$ and Queensland, Australia, ${ }^{32}$ the proportions of $\mathrm{T} 1$ tumors among $\mathrm{CM}$ patients with fatal outcome were $27 \%$ and $23 \%$, respectively, ie, higher than that in the present study (12.1\%). The NM/SSM ratio was 0.79 among the fatal CM cases in SEER in $1978-2007^{33}$ and 1.45 in Victoria, Australia, in 1989-2004. ${ }^{34}$ In Sweden, conflicting ratios for fatal CM have been published for local disease: 1.38 for $1990-1999^{20}$ and 0.5 for $1989-2003 .{ }^{35}$ We found an NM/SSM ratio of 1.4 for fatal CM and 1.1 for $\mathrm{CM}$ with local disease at diagnosis. Hence, the proportion of NM compared to SSM, both in incident and fatal cases, seems to be high in Norway compared to most other population-based registries. In SEER, the contribution of NM to fatal CM (excluding unspecified) was reported to be stable between 1978 and 2007 (37\%) and SSM was the largest contributor to CM-specific death (46\%). ${ }^{33}$ In our study and in the study from Victoria, Australia, ${ }^{34} \mathrm{NM}$ was the main contributor to CM-specific death, $55 \%$ and $50 \%$, respectively. Symmetrical NM is more easily misdiagnosed compared to SSM, ${ }^{36}$ and a low diagnostic sensitivity for NM compared to SSM is documented. ${ }^{37}$ Tumors of the NM type are escaping the established asymmetry, border, color, diameter, evolving $(\mathrm{ABCD}[\mathrm{E}])$ diagnostic guideline, ${ }^{38}$ which affects awareness and thus prognosis. We found an association between melanoma subtype and CM-specific death in crude analysis only, in line with the literature, which states that the prognostic significance of melanoma subtype is due to tumor thickness. ${ }^{4} \mathrm{CMs}$ with high growth rate are associated with male sex, age $>70$ years, as well as symmetry and elevation of the lesion, ${ }^{39}$ which together with low awareness, may explain the high mortality rate in Norway.

Individuals with a history of $\mathrm{CM}$ are found to have an increased risk of a second $\mathrm{CM}$ diagnosis,${ }^{40}$ and this may have an effect on survival in $\mathrm{CM}$. We found that multiple primary CMs during the study period are a prognostic factor for CMspecific death, in accordance with a study by Rowe et al. ${ }^{41}$

The main limitation of this study is the proportion of cases with missing clinical and histopathological data. We found that cases with unspecified data on T-stage had elevated risk of CM-specific death, indicating more advanced disease in these patients. Lack of information may result from incomplete diagnostic procedures in cases with thick tumors, distant metastases, or an unknown primary tumor. We had complete data on the anatomic site, melanoma subtype, Breslow thickness, ulceration, and clinical stage for $61.7 \%$ of the patients, a proportion in line with the Swedish data from 1990-1999 (65.1\%). ${ }^{20}$ According to the Norwegian guidelines for diagnosis, treatment, and follow-up of CM in the period 2008-2015, ${ }^{14}$ no modifications have been done with regard to reporting and registration of clinical stage, Clark, subtype, or Breslow thickness during the study period. We used multiple imputation to impute missing data, and importantly, results from the Cox regression analyses of the prognostic factors were similar for the imputed and the complete-case data. Unfortunately, information on comorbidity was not available. This may be of particular importance for diagnostic procedures and mortality prediction in elderly 
patients. Information on education and ethnicity was not available. Educational level may influence sun exposure habits, health concerns, and doctor delay. Ethnicity may be of less relevance as Norway has a public health care system that aims to provide equal access to health care. Furthermore, except for breast cancer, no stage-based differences at diagnosis were observed between immigrant groups and Norwegians in a recent study. ${ }^{42}$

During the final part of the study period, immunotherapies and kinase inhibitors have been implemented in the treatment of advanced CM in Norway. Thus, future comparisons of survival and mortality data must take secular trends into account, as new treatments for distant metastases are emerging.

\section{Conclusion}

The high mortality rates among Norwegian CM patients may be explained by the more-advanced disease stage at diagnosis compared with the rates among CM patients in other countries. The high proportion of NM may contribute to high mortality rates, and the occurrence of more-advanced disease in men can explain the difference seen between the sexes. The results indicate an impact of patient delay because the highest incidence rates, the worst prognostic factors, and the highest risk of CM-specific death are found among older patients, especially among men; hence, efforts should be made to improve secondary prevention of $\mathrm{CM}$ in these patients. The clinical characteristics of NM must be communicated to both health care professionals and the public for increased awareness.

\section{Availability of data and material}

The dataset analyzed during the current study is available at the Cancer Registry of Norway on reasonable request.

\section{Acknowledgments}

We would like to thank Siri Larønningen and Hilde Hedemann Brenn of the Cancer Registry of Norway (CRN), as well as the Norwegian Melanoma Group, for supply of data.

\section{Author contributions}

All authors contributed toward data analysis, drafting and critically revising the paper, gave final approval of the version to be published, and agree to be accountable for all aspects of the work.

\section{Disclosure}

The authors report no conflicts of interest in this work.

\section{References}

1. Forsea AM, Del Marmol V, de Vries E, Bailey EE, Geller AC. Melanoma incidence and mortality in Europe: new estimates, persistent disparities. Br J Dermatol. 2012;167(5):1124-1130.

2. Cancer Registry of Norway. Cancer in Norway 2016-Cancer Incidence, Mortality, Survival and Prevalence in Norway. Oslo: Cancer Registry of Norway; 2017.

3. Balch CM, Gershenwald JE, Soong SJ, et al. Final version of 2009 AJCC melanoma staging and classification. J Clin Oncol. 2009;27(36): 6199-6206.

4. Scolyer RA, Judge MJ, Evans A, et al; International Collaboration on Cancer Reporting. Data set for pathology reporting of cutaneous invasive melanoma: recommendations from the international collaboration on cancer reporting (ICCR). Am J Surg Pathol. 2013;37(12):1797-1814.

5. Amin MB, Greene FL, Edge SB, et al. The eighth edition AJCC cancer staging manual: continuing to build a bridge from a population-based to a more "personalized" approach to cancer staging. CA Cancer J Clin. 2017;67(2):93-99.

6. Tryggvadóttir L, Gislum M, Hakulinen T, et al. Trends in the survival of patients diagnosed with malignant melanoma of the skin in the Nordic countries 1964-2003 followed up to the end of 2006. Acta Oncol. 2010;49(5):665-672.

7. Lyth J, Eriksson H, Hansson J, et al. Trends in cutaneous malignant melanoma in Sweden 1997-2011: thinner tumours and improved survival among men. Br J Dermatol. 2015;172(3):700-706.

8. Bay C, Kejs AM, Storm HH, Engholm G. Incidence and survival in patients with cutaneous melanoma by morphology, anatomical site and TNM stage: a Danish Population-Based Register study 1989-2011. Cancer Epidemiol. 2015;39(1):1-7.

9. Robsahm TE, Bergva G, Hestvik UE, Moller B. Sex differences in rising trends of cutaneous malignant melanoma in Norway, 1954-2008. Melanoma Res. 2013;23(1):70-78.

10. Autier P, Koechlin A, Boniol M. The forthcoming inexorable decline of cutaneous melanoma mortality in light-skinned populations. Eur $J$ Cancer. 2015;51(7):869-878.

11. Weyers W. The 'epidemic' of melanoma between under- and overdiagnosis. J Cutan Pathol. 2012;39(1):9-16.

12. Larsen IK, Smastuen M, Johannesen TB, et al. Data quality at the Cancer Registry of Norway: an overview of comparability, completeness, validity and timeliness. Eur J Cancer. 2009;45(7):1218-1231.

13. World Health Organization. International Classification of Diseases for Oncology. Third Edition, First Revision ed. Geneva: World Health Organization; 2013.

14. The National Guidelines for Diagnosis, Treatment and Follow-Up of Malignant Melanomas. Norwegian: Directorate of Health. Available from: https://helsedirektoratet.no/retningslinjer/nasjonalt-handlingsprogram-med-retningslinjer-for-diagnostikk-behandling-og-oppfolging-av-maligne-melanomer. Accessed September 1, 2017.

15. Andersen PK, Geskus RB, de Witte T, Putter H. Competing risks in epidemiology: possibilities and pitfalls. Int $J$ Epidemiol. 2012;41(3):861-870.

16. Satagopan JM, Ben-Porat L, Berwick M, Robson M, Kutler D, Auerbach AD. A note on competing risks in survival data analysis. Br J Cancer. 2004;91(7):1229-1235.

17. Pintilie M. An introduction to competing risks analysis. Rev Esp Cardiol. 2011;64(7):599-605.

18. Khosrotehrani K, Dasgupta P, Byrom L, Youlden DR, Baade PD, Green AC. Melanoma survival is superior in females across all tumour stages but is influenced by age. Arch Dermatol Res. 2015;307(18):731-740.

19. White IR, Royston P, Wood AM. Multiple imputation using chained equations: issues and guidance for practice. Stat Med. 2011;30(4):377-399.

20. Lindholm C, Andersson R, Dufmats M, et al; Swedish Melanoma Study Group. Invasive cutaneous malignant melanoma in Sweden, 1990-1999. A prospective, population-based study of survival and prognostic factors. Cancer. 2004;101(9):2067-2078. 
21. Garbe C, McLeod GR, Buettner PG. Time trends of cutaneous melanoma in Queensland, Australia and Central Europe. Cancer. 2000;89(6):1269-1278.

22. Criscione VD, Weinstock MA. Melanoma thickness trends in the United States, 1988-2006. J Invest Dermatol. 2010;130(3):793-797.

23. Baade P, Meng X, Youlden D, Aitken J, Youl P. Time trends and latitudinal differences in melanoma thickness distribution in Australia, 1990-2006. Int J Cancer. 2012;130(1):170-178.

24. Kruijff S, Bastiaannet E, Francken AB, Schaapveld M, van der Aa M, Hoekstra HJ. Breslow thickness in the Netherlands: a population-based study of 40880 patients comparing young and elderly patients. $\mathrm{Br} J$ Cancer. 2012;107(3):570-574.

25. Shaikh WR, Dusza SW, Weinstock MA, Oliveria SA, Geller AC, Halpern AC. Melanoma thickness and survival trends in the United States, 1989 to 2009. J Natl Cancer Inst. 2015;108(1):djv294.

26. Lasithiotakis K, Leiter U, Meier F, et al. Age and gender are significant independent predictors of survival in primary cutaneous melanoma. Cancer. 2008;112(8):1795-1804.

27. Magnus K. The Nordic profile of skin cancer incidence. A comparative epidemiological study of the three main types of skin cancer. Int $J$ Cancer. 1991;47(1):12-19.

28. Balch CM, Soong S, Ross MI, et al. Long-term results of a multiinstitutional randomized trial comparing prognostic factors and surgical results for intermediate thickness melanomas (1.0 to $4.0 \mathrm{~mm})$. Intergroup Melanoma Surgical Trial. Ann Surg Oncol. 2000;7(2):87-97.

29. Jimenez RE, Panageas K, Busam KJ, Brady MS. Prognostic implications of multiple lymphatic basin drainage in patients with truncal melanoma. $J$ Clin Oncol. 2005;23(3):518-524.

30. Shaikh WR, Weinstock MA, Halpern AC, Oliveria SA, Geller AC, Dusza $\mathrm{SW}$. The characterization and potential impact of melanoma cases with unknown thickness in the United States' Surveillance, Epidemiology, and End Results Program, 1989-2008. Cancer Epidemiol. 2013;37(1):64-70.

31. Månsson-Brahme E, Johansson H, Singnomklao T, Larson O, Rutquist LE, Ringborg U. Time Trends in Survival in Cutaneous Malignant Melanoma; a Population-Based Study in Sweden. In: Cutaneous Malignant Melanoma. Aspects on Prognostical Factors and Time-Trends in a Swedish Population [thesis]. Paper 11, 1-28. Stockholm: Karolinska University Press; 2002.
32. Whiteman DC, Baade PD, Olsen CM. More people die from thin melanomas ( $1 \mathrm{~mm})$ than from thick melanomas $(>4 \mathrm{~mm})$ in Queensland, Australia. J Invest Dermatol. 2015;135(4):1190-1193.

33. Shaikh WR, Xiong M, Weinstock MA. The contribution of nodular subtype to melanoma mortality in the United States, 1978 to 2007. Arch Dermatol. 2012;148(1):30-36.

34. Mar V, Roberts H, Wolfe R, English DR, Kelly JW. Nodular melanoma: a distinct clinical entity and the largest contributor to melanoma deaths in Victoria, Australia. J Am Acad Dermatol. 2013;68(4):568-575.

35. Eriksson H, Frohm-Nilsson M, Jaras J, et al. Prognostic factors in localized invasive primary cutaneous malignant melanoma: results of a large population-based study. Br J Dermatol. 2015;172(1): 175-186.

36. Cicchiello M, Lin MJ, Pan Y, McLean C, Kelly JW. An assessment of clinical pathways and missed opportunities for the diagnosis of nodular melanoma versus superficial spreading melanoma. Australas J Dermatol. 2016;57(2):97-101.

37. Lin MJ, Mar V, McLean C, Wolfe R, Kelly JW. Diagnostic accuracy of malignant melanoma according to subtype. Australas J Dermatol. 2014;55(1):35-42.

38. McGovern TW, Litaker MS. Clinical predictors of malignant pigmented lesions. A comparison of the Glasgow seven-point checklist and the American Cancer Society's ABCDs of pigmented lesions. J Dermatol Surg Oncol. 1992;18(1):22-26.

39. Liu W, Dowling JP, Murray WK, et al. Rate of growth in melanomas: characteristics and associations of rapidly growing melanomas. Arch Dermatol. 2006;142(12):1551-1558.

40. Robsahm TE, Karagas MR, Rees JR, Syse A. New malignancies after squamous cell carcinoma and melanomas: a population-based study from Norway. BMC Cancer. 2014;14:210.

41. Rowe CJ, Law MH, Palmer JM, MacGregor S, Hayward NK, Khosrotehrani K. Survival outcomes in patients with multiple primary melanomas. J Eur Acad Dermatol Venereol. 2015;29(11): 2120-2127.

42. Thøgersen H, Møller B, Robsahm TE, Aaserud S, Babigumira R, Larsen IK. Comparison of cancer stage distribution in the immigrant and host populations of Norway, 1990-2014. Int J Cancer. 2017;141(1): $52-61$. 


\section{Supplementary materials}

Table SI Distribution of the imputed variables

\begin{tabular}{|c|c|c|c|}
\hline Characteristics & Total & Women & Men \\
\hline \multicolumn{4}{|c|}{ Anatomic site, $n=477$} \\
\hline Trunk & 47.6 & 35.5 & 59.9 \\
\hline Head/neck & 14.4 & 13.2 & 15.6 \\
\hline Arm & 13.8 & 16.6 & 11.0 \\
\hline Leg & 23.6 & 34.1 & 13.0 \\
\hline Other & 0.6 & 0.6 & 0.6 \\
\hline \multicolumn{4}{|c|}{ Melanoma subtype, $n=2 \mid 26$} \\
\hline Superficial spreading & 66.1 & 68.6 & 63.6 \\
\hline Nodular & 27.2 & 24.4 & 30.0 \\
\hline Lentigo maligna & 3.9 & 4.7 & 3.2 \\
\hline Other & 2.8 & 2.4 & 3.2 \\
\hline \multicolumn{4}{|l|}{ T-stage, $n=857$} \\
\hline $\mathrm{TI}(\leq \mathrm{I} .0 \mathrm{~mm})$ & 50.2 & 54.6 & 45.8 \\
\hline $\mathrm{T} 2(\mathrm{I} .0 \mathrm{I}-2.0 \mathrm{~mm})$ & 21.2 & 21.2 & 21.2 \\
\hline T3 $(2.01-4.0 \mathrm{~mm})$ & 15.7 & 13.2 & 18.2 \\
\hline $\mathrm{T} 4(>4.0 \mathrm{~mm})$ & 12.9 & 11.0 & 14.8 \\
\hline \multicolumn{4}{|l|}{ Ulceration, n=3638 } \\
\hline Present & 26.3 & 22.5 & 30.1 \\
\hline Not present & 73.7 & 77.5 & 69.9 \\
\hline \multicolumn{4}{|c|}{ Clinical stage, $n=1$ | | 6} \\
\hline Local & 91.1 & 93.1 & 89.1 \\
\hline Regional metastasis & 5.4 & 4.2 & 6.6 \\
\hline Distant metastasis & 3.5 & 2.6 & 4.4 \\
\hline
\end{tabular}

Table S2 HRs for CM death, with $95 \%$ Cls, by sex, age, anatomic site, melanoma subtype, T-stage, ulceration, clinical stage, and presence of a second primary CM from crude and multivariate analyses of complete-case data $(n=5010)$

\begin{tabular}{|c|c|c|c|c|c|}
\hline \multirow[t]{2}{*}{$\overline{\text { Characteristics }}$} & \multirow[t]{2}{*}{ CM-specific death, $n$} & \multicolumn{2}{|c|}{ Crude analysis } & \multicolumn{2}{|c|}{ Multivariate analysis } \\
\hline & & HR & $95 \% \mathrm{Cl}$ & HR & $95 \% \mathrm{Cl}$ \\
\hline \multicolumn{6}{|l|}{$\overline{\text { Sex }}$} \\
\hline Women & 85 & 1.00 & & 1.00 & \\
\hline Men & 164 & 2.00 & $1.54-2.60$ & 1.33 & $1.00-1.76$ \\
\hline \multicolumn{6}{|l|}{ Age (years) } \\
\hline$<50$ & 25 & 1.00 & & 1.00 & \\
\hline $50-69$ & 93 & 1.98 & $1.27-3.08$ & 1.28 & $0.82-2.00$ \\
\hline$\geq 70$ & 131 & 4.02 & $2.62-6.17$ & 1.81 & $1.17-2.82$ \\
\hline \multicolumn{6}{|l|}{ Anatomic site } \\
\hline Trunk & 137 & 1.00 & & 1.00 & \\
\hline Head/neck & 34 & 0.92 & $0.63-1.35$ & 0.62 & $0.42-0.92$ \\
\hline Arm & 31 & 0.77 & $0.52-1.13$ & 0.71 & $0.48-1.06$ \\
\hline Leg & 43 & 0.62 & $0.44-0.87$ & 0.78 & $0.54-1.12$ \\
\hline Other & 4 & 0.73 & $0.27-1.98$ & 0.79 & $0.29-2.15$ \\
\hline \multicolumn{6}{|l|}{ Melanoma subtype } \\
\hline Superficial spreading & 93 & 1.00 & & 1.00 & \\
\hline Nodular & 145 & 4.50 & $3.47-5.84$ & 0.91 & $0.66-1.25$ \\
\hline Lentigo maligna & 4 & 0.82 & $0.30-2.24$ & 1.04 & $0.36-2.96$ \\
\hline Other & 7 & 2.53 & I.17-5.45 & 0.52 & $0.23-1.17$ \\
\hline \multicolumn{6}{|l|}{ T-stage } \\
\hline TI $(\leq \mathrm{I} .0 \mathrm{~mm})$ & 26 & 1.00 & & 1.00 & \\
\hline $\mathrm{T} 2(\mathrm{I} .0 \mathrm{I}-2.0 \mathrm{~mm})$ & 42 & 4.23 & $2.60-6.91$ & 3.59 & $2.19-5.91$ \\
\hline T3 $(2.0 \mathrm{I}-4.0 \mathrm{~mm})$ & 76 & 11.03 & $7.07-17.22$ & 7.97 & $4.81-13.19$ \\
\hline $\mathrm{T} 4(>4.0 \mathrm{~mm})$ & 105 & 26.38 & $17.16-40.54$ & 13.97 & $8.24-23.66$ \\
\hline
\end{tabular}


Table S2 (Continued)

\begin{tabular}{|c|c|c|c|c|c|}
\hline \multirow[t]{2}{*}{ Characteristics } & \multirow[t]{2}{*}{ CM-specific death, n } & \multicolumn{2}{|c|}{ Crude analysis } & \multicolumn{2}{|c|}{ Multivariate analysis } \\
\hline & & HR & $95 \% \mathrm{Cl}$ & HR & $95 \% \mathrm{Cl}$ \\
\hline \multicolumn{6}{|l|}{ Ulceration } \\
\hline Present & 105 & 4.94 & $3.84-6.36$ & 1.37 & $1.04-1.82$ \\
\hline Not present & 144 & 1.00 & & 1.00 & \\
\hline \multicolumn{6}{|l|}{ Clinical stage } \\
\hline Local & 153 & 1.00 & & 1.00 & \\
\hline Regional metastasis & 71 & 12.26 & $9.25-16.27$ & 5.39 & $3.97-7.32$ \\
\hline Distant metastasis & 25 & 40.24 & $26.27-6 I .64$ & 19.32 & $12.40-30.08$ \\
\hline \multicolumn{6}{|c|}{ Second primary CM } \\
\hline 0 & 235 & 1.00 & & 1.00 & \\
\hline I & II & 1.87 & $1.02-3.43$ & 3.81 & $2.03-7.13$ \\
\hline$>1$ & 3 & 3.65 & $1.16-11.47$ & 7.71 & $2.38-24.98$ \\
\hline
\end{tabular}

Abbreviations: $\mathrm{Cl}$, confidence interval; $\mathrm{CM}$, cutaneous melanoma; $\mathrm{HR}$, hazard ratio.

\section{Publish your work in this journal}

Clinical Epidemiology is an international, peer-reviewed, open access, online journal focusing on disease and drug epidemiology, identification of risk factors and screening procedures to develop optimal preventative initiatives and programs. Specific topics include: diagnosis, prognosis, treatment, screening, prevention, risk factor modification,

Submit your manuscript here: https://www.dovepress.com/clinical-epidemiology-journal systematic reviews, risk and safety of medical interventions, epidemiology and biostatistical methods, and evaluation of guidelines, translational medicine, health policies and economic evaluations. The manuscript management system is completely online and includes a very quick and fair peer-review system, which is all easy to use. 